\title{
Prevention of Ventilator-Associated Pneumonia: Can Knowledge and Clinical Practice Be Simply Assessed in a Large Institution?
}

\author{
María Jesús Pérez-Granda RN, Patricia Muñoz MD PhD, Carmen Heras RN, \\ Guiomar Sánchez RN, Jordi Rello MD PhD, and Emilio Bouza MD PhD, \\ on behalf of Grupo de Ayuda a la Neumonía Grave (GANG)
}

\begin{abstract}
OBJECTIVE: User-friendly scores to assess knowledge of guidelines for prevention of ventilatorassociated pneumonia (VAP) are scarce and have mainly evaluated nurses, but not students or physicians. Gaps between knowledge and actual clinical practice have not been sufficiently analyzed. We assessed knowledge of and adherence to guidelines for prevention of VAP among physicians, nurses, and students in adult ICUs. METHODS: All adult ICU healthcare workers were invited to complete a 20-point questionnaire. The first part assessed personal knowledge of international guidelines for prevention of VAP; the second part assessed daily clinical practice. Personal knowledge and daily practice were scored from 0 to 10 points. RESULTS: We invited 257 ICU healthcare workers to participate in the study, and 167 (65\%) accepted (32/54 physicians, 108/176 nurses, and 27/27 students). The median (IQR) personal knowledge scores for physicians, nurses, and students were $6(5-7), 5(4-6)$, and 5 (4-7), respectively. The median scores for daily clinical practice for physicians and nurses were 5 (4-6) and 4 (3-5), respectively. Healthcare workers with more than 1 year of ICU experience scored significantly better in personal knowledge than those with less experience: 6 (5-7) versus 4 (3-6), $P=.004$. CONCLUSIONS: A simple, easy-to-complete questionnaire enabled us to rapidly evaluate personal knowledge and reported clinical practice in prevention of VAP in large teaching institutions. These scores will be used as baseline figures to assess the impact of educational and intervention campaigns. Key words: ventilator-associated pneumonia; prevention; knowledge; intensive care. [Respir Care 2013;58(7):1213-1219. () 2013 Daedalus Enterprises]
\end{abstract}

\section{Introduction}

Ventilator-associated pneumonia (VAP) is the most frequent infection in patients admitted to ICUs, ${ }^{1-6}$ and is as-

Drs Pérez-Granda, Muñoz, and Bouza are affiliated with the Ciber de Enfermedades Respiratorias (CIBERES); Drs Muñoz and Bouza are affiliated with the Department of Clinical Microbiology and Infectious Diseases; Drs Pérez-Granda, Heras, and Rello are affiliated with the Department of Anesthesiology; and Dr Sánchez is affiliated with the Medical ICU, Hospital General Universitario Gregorio Marañón, Universidad Complutense, Madrid, Spain. Dr Rello is also affiliated with the ICU, Hospital Vall D’Hebron, Barcelona, Spain.

Supplementary material related to this paper is available at http://www. rcjournal.com.

This research was partly supported by Centro de Investigación Bio- sociated with an increase in days of ICU stay, morbidity and mortality. ${ }^{2-4,7,8}$ Prevention of VAP is much more costeffective than treatment, and several guidelines have recommended measures to decrease the incidence of VAP. ${ }^{9-15}$ The most important measures are continuous medical education, ${ }^{16-18}$ continuous suctioning of subglottic secre-

\footnotetext{
médica en Red de Enfermedades Respiratorias, the Intrasalud Project, and the Rafael del Pino Foundation. The authors have disclosed no conflicts of interest.

Correspondence: Patricia Muñoz MD PhD, Servicio de Microbiología Clínica y Enfermedades Infecciosas, Hospital General Universitario Gregorio Marañón, Calle del Doctor Esquerdo, 4628007 Madrid, Spain. E-mail: pmunoz@micro.hggm.es.
}

DOI: $10.4187 /$ respcare.01854 
tions, ${ }^{19}$ semi-recumbent position, ${ }^{11,20-25}$ oral hygiene with chlorhexidine, ${ }^{26}$ and selective digestive decontamination. $6,27-31$

Knowledge of guidelines for prevention of VAP among healthcare workers (HCWs) has been infrequently assessed and mainly in staff nurses only. The gaps between individual knowledge of VAP prevention and actual daily clinical practice have not been compared.26,32-36

Our objective was to assess and compare the knowledge of physicians, staff nurses, and medical and nursing students in adult ICUs and their adherence to guidelines in daily practice.

\section{Methods}

\section{Hospital and Patients}

Our institution is a general referral hospital with approximately 1,550 beds and between 50,000 and 60,000 admissions/year. We have 3 adult ICUs (medical, surgical, and heart surgery) with a total of 58 beds.

\section{Participating Healthcare Workers}

All staff physicians, nurses, and students in the 3 ICUs were invited to participate in the study by completing an anonymous questionnaire (Table 1). As respiratory therapists in our institution attend only non-ventilated patients or chronically ventilated patients (tracheostomy), they were not included in the study.

The ethics committee approved the study. We asked 10 questions related to personal knowledge of VAP prevention. Each question included 5 potential multiple-choice answers. A correct answer scored 1 point; therefore, the maximum score was 10 points and the minimum score 0 points. An incorrect answer did not affect the score negatively. Participants were given $15 \mathrm{~min}$ to complete the questionnaire, which was then collected by one of the authors. This survey was conducted in December 2010.

The knowledge questionnaire (see the supplementary materials at http://www.rcjournal.com) was elaborated and discussed by all the authors, and internally evaluated by a panel of experts on VAP in our institution, following international recommendations (International Organization for Standardization standard 9001:2008). The correct answers were based on internationally accepted guidelines and carefully discussed by the hospital panel of experts. ${ }^{9-11,15}$ Questions were answered according to different guidelines, although the arguments were generally sustained by most of them. When there were discrepancies between the guidelines, such as in the level of recommendation of selective digestive decontamination, the most common option was considered the correct answer.

\section{QUICK LOOK}

\section{Current knowledge}

Ventilator-associated pneumonia (VAP) is the most common infection in ICU patients, and is associated with longer ICU stay and increased morbidity and mortality. VAP prevention measures are cost-effective, compared to treatment, and prevention typically involves a set of interventions referred to as a bundle. Knowledge about VAP prevention varies between individuals and institutions.

\section{What this paper contributes to our knowledge}

Knowledge about VAP prevention varied widely among surveyed physicians and nurses. Knowledge gaps affect the implementation and monitoring of VAP prevention practices. Continuing education remains imperative.

We followed the same approach in the actual practice questionnaire, although excluding medical and nursing students, who had no basic responsibility. Table 2 summarizes the questions and the interpretation of answers. This questionnaire was elaborated and validated in the same way as the knowledge questionnaire.

\section{Statistical Analysis}

The qualitative variables appear with their frequency distributions. The quantitative variables are summarized as medians and interquartile ranges. Non-normally distributed continuous variables were compared using the MannWhitney test. The chi-square or Fisher exact test was used to compare categorical variables. All statistical tests were 2 -tailed. The level of significance was set at $P<.05$ for all the tests. The statistical analysis was performed with statistics software (SPSS 14.0, SPSS, Chicago, Illinois, and Stata 9.0, StataCorp, College Station, Texas).

We used the Pearson correlation test to assess the correlation between knowledge and practice scores in the nurses and physicians subgroups. Inter-subject agreement was assessed by the intra-class correlation coefficient (SPSS reliability test, averaged-measures intra-class correlation coefficient).

\section{Results}

The questionnaire was completed by 167 of the 257 ICU HCWs invited to participate (65.0\%). Of these, 32 were physicians (59.3\%), 108 were nurses (61.4\%), and 27 were students (100\%) (see Table 1). As for the physicians' specialty, 10 were intensivists and 22 anesthesiologists. 
Table 1. Number of Health Care Workers in the ICUs

\begin{tabular}{lcccc}
\hline \hline & Physicians & Nurses & Students & Total \\
\hline Overall & 54 & 176 & 27 & 257 \\
Participating, no. (\%) & $32(59.3)$ & $108(61.4)$ & $27(100)$ & $167(65.0)$ \\
Medical ICU & 10 & 30 & 11 & 51 \\
Surgical ICU & 10 & 42 & 12 & 64 \\
Heart surgery ICU & 12 & 36 & 4 & 52 \\
\hline
\end{tabular}

Agreement to participate was significantly different between students and nurses/physicians $(P<.001)$.

Table 2 summarizes the questions assessing knowledge, the criteria used for evaluation of adequacy, and the proportion of adequate answers per question and $\mathrm{HCW}$ group.

Only the need to have written guidelines and the use of a semi-recumbent position were adequately recognized by more than $90 \%$ of the HCWs. On the other hand, the need for postoperative physiotherapy and the necessary frequency of ventilator circuit changes were adequately known by less than $10 \%$ of HCWs. We were unable to find significant differences between the knowledge of physicians and nurses in 7 of the 10 questions. Knowledge of the need for hand hygiene and gloves before manipulation and tra- cheal suctioning was significantly better in nurses $(P<.01)$; knowledge of the change of ventilator circuits was better among physicians $(P<.01)$. Physicians seem to have a better knowledge than nurses of the concept of selective digestive decontamination and the controversy surrounding its efficacy and potential drawbacks $(P<.001)$.

We also studied if there was a common knowledge shared by all the personnel in each ICU. The intraclass correlation coefficient showed a significant agreement in 2 of the ICUS (surgical ICU $\rho=0.52, P=.005$; heart surgery ICU $\rho=0.55, P=.004)$, but the agreement was lower in the medical ICU $(\rho=0.37, P=.07)$. Inter-subject agreement was high.

Answers related to actual daily practice in HCWs caring for patients under mechanical ventilation are summarized in Table 3. As mentioned above, we excluded students from the practice score, since they were not directly involved in practice. The only practices properly performed more than $80 \%$ of the time were the semi-recumbent position and assessment of endotracheal balloon pressure.

We used the medians of points obtained in the knowledge questionnaire to create a knowledge score scale (Table 4). The median knowledge score was 5 points (IQR $4-$ 6 ), and the median practice score was 4 points (IQR 3-5).

Table 2. Assessment of Individual Knowledge, by Professional Level

\begin{tabular}{|c|c|c|c|c|c|c|c|c|}
\hline \multirow{2}{*}{$\begin{array}{l}\text { Question } \\
\text { Number }\end{array}$} & \multirow{2}{*}{ Question } & \multirow{2}{*}{$\begin{array}{l}\text { References } \\
\text { for } \\
\text { Answers }\end{array}$} & \multirow{2}{*}{ Adequate Answer } & \multicolumn{4}{|c|}{ Percentage of Adequate Answers } & \multirow[b]{2}{*}{$P$} \\
\hline & & & & Overall & Physicians & Nurses & Students & \\
\hline 1 & $\begin{array}{l}\text { How do you value the need to have written } \\
\text { guidelines for the prevention of VAP in } \\
\text { your unit? }\end{array}$ & $9-11,15$ & Highly needed or needed & 95.2 & 96.9 & 95.4 & 92.5 & .37 \\
\hline 2 & $\begin{array}{l}\text { Evolution of VAP in the ICU must be } \\
\text { recorded as ... }\end{array}$ & $9-11,15$ & Incidence and incidence density & 64.7 & 75.0 & 63.0 & 59.3 & .20 \\
\hline 3 & $\begin{array}{l}\text { The semi-recumbent position for the } \\
\text { prevention of VAP is considered ... }\end{array}$ & $9-11,15$ & $\begin{array}{l}\text { Highly recommended or } \\
\text { recommended }\end{array}$ & 92.8 & 96.9 & 92.6 & 88.9 & .43 \\
\hline 4 & $\begin{array}{l}\text { What is the most recommended procedure } \\
\text { for oral hygiene to prevent VAP? }\end{array}$ & 9,10 & Chlorhexidine $0.12 \%$ & 68.3 & 78.1 & 63.9 & 74.1 & .27 \\
\hline 5 & $\begin{array}{l}\text { What is your opinion regarding respiratory } \\
\text { physiotherapy for the prevention of } \\
\text { VAP? }\end{array}$ & & There is no evidence of efficacy & 4.2 & 9.4 & 3.7 & 0.0 & .27 \\
\hline 6 & $\begin{array}{l}\text { Barrier measures (hand hygiene and } \\
\text { gloves) before tracheal suctioning and } \\
\text { manipulation of ventilator circuits are } \ldots\end{array}$ & $9-11,15$ & Highly recommended & 58.1 & 37.5 & 63.9 & 59.3 & $<.01$ \\
\hline 7 & $\begin{array}{l}\text { The recommendation for subglottic } \\
\text { suctioning of respiratory secretions is ... }\end{array}$ & $9-11$ & $\begin{array}{l}\text { Highly recommended or } \\
\text { recommended }\end{array}$ & 31.2 & 46.9 & 25.0 & 36.0 & .91 \\
\hline 8 & $\begin{array}{l}\text { When should ventilator circuits be } \\
\text { changed? }\end{array}$ & $9-11,15$ & $\begin{array}{l}\text { When soiled or dirty or after } \\
\text { each patient }\end{array}$ & 7.2 & 28.1 & 2.8 & 0.0 & $<.01$ \\
\hline 9 & $\begin{array}{l}\text { Control and maintenance of pressure of the } \\
\text { tracheal balloon in patients undergoing } \\
\text { subglottic suctioning is ... }\end{array}$ & 10,15 & $\begin{array}{l}\text { Highly recommended or } \\
\text { recommended }\end{array}$ & 85.7 & 90.7 & 85.2 & 24.8 & .39 \\
\hline 10 & $\begin{array}{l}\text { Selective digestive decontamination with } \\
\text { antibiotics is ... }\end{array}$ & 10,15 & $\begin{array}{l}\text { Not generally recommended at } \\
\text { present }\end{array}$ & 26.3 & 56.3 & 18.5 & 22.2 & $<.01$ \\
\hline
\end{tabular}

$\mathrm{VAP}=$ ventilator-associated pneumonia 
Table 3. Assessment of Daily Clinical Practice in the Prevention of Ventilator-Associated Pneumonia

\begin{tabular}{|c|c|c|c|c|}
\hline \multirow{2}{*}{$\begin{array}{l}\text { Question } \\
\text { Number }\end{array}$} & \multirow{2}{*}{ Question } & \multicolumn{3}{|c|}{ Percentage of Positive Answers } \\
\hline & & Overall & Physicians & Nurses \\
\hline 1 & Do you know the written guidelines of your unit? & 25.9 & 31.3 & 24.1 \\
\hline 2 & $\begin{array}{l}\text { Are you aware of the evolution of figures of incidence and incidence density } \\
\text { of VAP in your unit? }\end{array}$ & 55.1 & 78.1 & 58.3 \\
\hline 3 & Do you keep your patients in a semi-recumbent position $\left(30-45^{\circ}\right)$ ? & 85 & 84.4 & 87.7 \\
\hline 4 & Do you regularly use chlorhexidine for oral decontamination? & 70.1 & 71.9 & 67.6 \\
\hline 5 & Do you regularly use respiratory physiotherapy to prevent VAP? & 3.0 & 3.1 & 2.8 \\
\hline 6 & Do you regularly disinfect hands and wear gloves before tracheal suctioning? & 31.1 & 21.9 & 35.2 \\
\hline 7 & In your unit, do you perform subglottic suctioning of respiratory secretions? & 10.2 & 3.1 & 11.1 \\
\hline 8 & Do you change ventilator-circuit tubes only when soiled or after each patient? & 22.2 & 53.2 & 13.9 \\
\hline 9 & Do you regularly control the pressure of the tracheal balloon during each shift? & 91.6 & 84.4 & 94.4 \\
\hline 10 & Do you regularly perform oral decontamination to prevent VAP? & 38.9 & 56.6 & 36.1 \\
\hline
\end{tabular}

Table 4. Comparison of Knowledge and Practice Scores by Professional Level and Years of Practice

\begin{tabular}{lcr}
\hline \hline & \multicolumn{2}{c}{ Median (IQR) Score } \\
\cline { 2 - 3 } & Knowledge & Practice \\
\hline Professional level & & \\
$\quad$ Physicians, $n=32$ & $6(5-7)$ & $5(4-6)$ \\
Nurses, $n=108$ & $5(4-6)$ & $4(3-5)$ \\
Students, $n=27$ & $5(4-7)$ & \\
& $P=.004$ & \\
Years of ICU experience & & \\
$\quad$ (students excluded) & & $4(3-5)$ \\
$\leq 5 \mathrm{y}, n=76$ & $5(4-6)$ & $5(4-6)$ \\
$>5 \mathrm{y}, n=64$ & $5(4-7)$ & $P<.001$ \\
& $P=.24$ & $4(2-4)$ \\
$<1 \mathrm{y}, n=22$ & $4(3-6)$ & $5(4-5)$ \\
$\geq 1 \mathrm{y}, n=118$ & $6(5-7)$ & $P=.003$ \\
& $P=.004$ & \\
\hline
\end{tabular}

The physicians' global knowledge and practice scores were significantly higher (see Table 4).

Table 4 also compares the combined scores of the physicians and nurses, according to their years of ICU experience. Those in practice for more than 1 year had better scores both in knowledge and in clinical practice. However, when HCWs with more or less than 5 years of ICU experience were compared, only the practice scores were significantly different $(P<.001)$.

When the physicians and nurses were studied separately, the knowledge score was significantly higher in physicians with more than 1 year of experience ( 7 vs $5, P=.007$ ) and in those with more than 5 years of experience ( 7 vs 6 , $P=.02)$. In the case of nurses the only significant cutoff was 1 year of experience ( 5 vs $4, P=.003$ ).
Finally, we analyzed the correlation between knowledge and reported practice scores in nurses and physicians. The nurses had a statistically significant correlation between both scores (Pearson correlation 0.31, $P=.001$ ). However, in the physicians the correlation did not reach statistical significance (Pearson correlation 0.22, $P=.20$ ).

\section{Discussion}

The evaluation of HCW knowledge of well accepted principles for the prevention of VAP revealed much room for improvement and the need for continuous education. In our study, knowledge was significantly different between the nurses and physicians, and it also varied with seniority in both groups

VAP remains the most common and severe nosocomial infection in ventilated patients, and is associated with a high degree of morbidity and mortality. $4,6,37$ Prevention is the main issue in VAP, and many groups and scientific societies have provided prevention guidelines in the last 10 years. $9,10,12,14,26,38,39$ Present guidelines, however, do not recommend a simple procedure to assess baseline knowledge of VAP prevention and the evolution of this knowledge after educational interventions.

Despite the existence of a hospital-approved protocol for the prevention of VAP, our study demonstrates that care provider knowledge is low and that it affects the implementation of the recommendations. Our study included nurses, physicians, and nursing and medical students. Although we found some differences between the overall knowledge scores of the physicians, nurses, and students, our study indicates that strategies to implement prevention guidelines should be common to all HCWs. In any case, the results of the evaluation of HCW knowledge of guidelines for prevention of VAP reported in the 
literature are deceptively low and far from satisfactory. ${ }^{26,33,34,40,41}$

We were able to find only a number of papers assessing the quality of knowledge of VAP prevention. ${ }^{16,21,26,33,34,40,42-44}$ Data regarding the assessment of knowledge have been obtained mainly in nurs$\mathrm{es}^{26,33,34,40,45-47}$ and only occasionally in physicians. ${ }^{16,35} \mathrm{In}$ 2007, Labeau et al ${ }^{47}$ reported the results of a questionnaire assessing critical care nurses' knowledge of evidence-based guidelines for preventing VAP. Ten nursing-related interventions were assessed from a review of evidence-based guidelines. The questionnaire was distributed to 22 European countries ${ }^{40}$ between October 2006 and March 2007. The average adequate score was $45.1 \%$. Only $55 \%$ of respondents knew that the oral route was recommended for intubation, and only 35\% knew that ventilator circuits should be changed for each new patient. Professional seniority and number of ICU beds were shown to be independently associated with better test scores. The assessment was aimed only at nurses and did not include other HCWs.

The same questionnaire was also evaluated in different subgroups, including nurses of the Flemish Society for Critical Care Nurses (Ghent, November 2005) ${ }^{33}$ and the nurses from several Mediterranean countries, ${ }^{26}$ with no significant differences between different European groups.

The low knowledge scores obtained in most of the reported assessments indicate that formidable efforts must be made in the education of all HCWs. ${ }^{20,32,48-50}$ Knowledge and actual clinical practice do not necessarily have to run in parallel, although our study shows that, unfortunately, they do. This means that to ensure proper practice, innovative techniques such as electronic and mechanical alarms have to be implemented, as do educational measures. ${ }^{20,32,48-50}$ Better strategies should be adopted at the bedside to eliminate erroneous behavior and attitudes. On the other hand, the implementation of some practices, such as subglottic suctioning of respiratory secretions or selective digestive decontamination, does not depend on personal knowledge or conviction, but on unit or hospital policies. Therefore, we evaluated knowledge of the recommendations and clinical practice separately.

Our results suggest that seniority indicates better knowledge and approaches to clinical practice, as do other studies. $26,33,35,40$ At the same time, the results claim for better compulsory educational programs for all staff involved or about to be involved in bedside care. As an example, question number 8 of Table 3 highlighted a considerable discrepancy between the practice of physicians and nurses with respect to changing ventilator circuit tubes. Our analysis of this aspect revealed that the official nurses' protocol was outdated and only recommended changing the circuits after 7 days. The protocol has now been modified. We also found that the physicians' evaluation was flawed, since, although their knowledge of the guidelines may be adequate, they are not aware of the practices performed only by nurses, thus stressing the need for close collaboration between the 2 groups. As an example, we can mention the poor physician score on question 6 of Table 3, on the need for disinfecting hands and wearing gloves before tracheal suctioning, a practice usually performed by nurses.

Our findings also reinforce the need for assessment with methods such as that reported in this paper. The results of this survey were used to design an educational program that has been delivered in all the ICUs of our institution.

We observed a significant correlation between knowledge and practice scores among nurses, but not among physicians, possibly because most of the questions dealt with practices performed by nurses.

Although our study has the advantage of including all healthcare professionals in the ICU, it is limited by the relatively small number of participants and the fact that it was performed in a single tertiary university hospital. Our study is also limited by the fact that the information given by the respondents (reported clinical practice) may not correspond with their actual clinical practice. In addition, some possible preventive measures were not included in our questionnaire (role of sedation, weaning protocols, and noninvasive ventilation). Our bundle of preventive measures was designed by our panel of experts, who chose those measures that were more amenable for intervention.

\section{Conclusions}

In our opinion, this simple, easily completed questionnaire may help large institutions to rapidly evaluate staff knowledge and real clinical practice in the prevention of VAP. These scores can be used as baseline figures to assess the impact of educational interventions.

\section{ACKNOWLEDGMENTS}

We are grateful to the staff physicians and nurses of our adult ICUs, the medical and nursing students who participated in this study, and Jose Francisco Granizo for his help with the statistical analysis.

\section{REFERENCES}

1. Zuschneid I, Schwab F, Geffers C, Behnke M, Ruden H, Gastmeier P. Trends in ventilator-associated pneumonia rates within the German nosocomial infection surveillance system (KISS). Infect Control Hosp Epidemiol 2007;28(3):314-318.

2. Bouza E, Hortal J, Muñoz P, Pascau J, Perez MJ, Hiesmayr M. Postoperative infections after major heart surgery and prevention of ventilator-associated pneumonia: a one-day European prevalence study (ESGNI-008). J Hosp Infect 2006;64(3):224-230.

3. Bouza E, Hortal J, Muñoz P, Perez MJ, Riesgo MJ, Hiesmayr M. Infections following major heart surgery in European intensive care units: there is room for improvement (ESGNI 007 Study). J Hosp Infect 2006;63(4):399-405. 


\section{Prevention of Ventilator-Associated Pneumonia}

4. Muscedere J. Ventilator-associated pneumonia and mortality: the controversy continues. Crit Care Med 2009;37(10):2845-2846.

5. Wunderink RG, Brun-Buisson C. Ventilator-associated pneumonia: lessons learned from clinical trials. J Crit Care 2008;23(1):2-4.

6. Kollef MH, Morrow LE, Niederman MS, Leeper KV, Anzueto A, Benz-Scott L, et al. Clinical characteristics and treatment patterns among patients with ventilator-associated pneumonia. Chest 2006; 129(5):1210-1218.

7. Valles J, Pobo A, Garcia-Esquirol O, Mariscal D, Real J, Fernandez R. Excess ICU mortality attributable to ventilator-associated pneumonia: The role of early vs late onset. Intensive Care Med 2007; 33(8):1363-1368

8. Niederman MS. Can optimal management prevent mortality in ventilator-associated pneumonia? Crit Care Med 2002;30(8):1916-1917.

9. Tablan OC, Anderson LJ, Besser R, Bridges C, Hajjeh R. Guidelines for preventing health-care-associated pneumonia, 2003: recommendations of CDC and the Healthcare Infection Control Practices Advisory Committee. MMWR Recomm Rep 2004;53(RR-3):1-36.

10. American Thoracic Society. Guidelines for the management of adults with hospital-acquired, ventilator-associated, and healthcare-associated pneumonia. Am J Respir Crit Care Med 2005;171(4):388-416.

11. Dodek P, Keenan S, Cook D, Heyland D, Jacka M, Hand L, et al. Evidence-based clinical practice guideline for the prevention of ventilator-associated pneumonia. Ann Intern Med 2004;141(4):305-313.

12. Mosier MJ, Pham TN. American Burn Association Practice guidelines for prevention, diagnosis, and treatment of ventilator-associated pneumonia (VAP) in burn patients. J Burn Care Res 2009;30(6):910928.

13. Coffin SE, Klompas M, Classen D, Arias KM, Podgorny K, Anderson DJ, et al. Strategies to prevent ventilator-associated pneumonia in acute care hospitals. Infect Control Hosp Epidemiol 2008;29(Suppl 1):S31-S40.

14. Muscedere J, Dodek P, Keenan S, Fowler R, Cook D, Heyland D. Comprehensive evidence-based clinical practice guidelines for ventilator-associated pneumonia: prevention. J Crit Care 2008;23(1): 126-137.

15. Torres A, Carlet J. Ventilator-associated pneumonia. European Task Force on ventilator-associated pneumonia. Eur Respir J 2001;17(5): 1034-1045.

16. Rello J, Lorente C, Bodi M, Diaz E, Ricart M, Kollef MH. Why do physicians not follow evidence-based guidelines for preventing ventilator-associated pneumonia? A survey based on the opinions of an international panel of intensivists. Chest 2002;122(2):656-661.

17. Apisarnthanarak A, Pinitchai U, Thongphubeth K, Yuekyen C, Warren DK, Zack JE, et al. Effectiveness of an educational program to reduce ventilator-associated pneumonia in a tertiary care center in Thailand: a 4-year study. Clin Infect Dis 2007;45(6):704-711.

18. Labeau SO, Vandijck DM, Vandewoude KH, Blot SI. Education reduces ventilator-associated pneumonia rates. Clin Infect Dis 2008; 46(3):479

19. Muscedere J, Rewa O, McKechnie K, Jiang X, Laporta D, Heyland DK. Subglottic secretion drainage for the prevention of ventilatorassociated pneumonia: a systematic review and meta-analysis. Crit Care Med 2011;39(8):1985-1991.

20. Bouza E, Burillo A. Advances in the prevention and management of ventilator-associated pneumonia. Curr Opin Infect Dis 2009;22(4): 345-351.

21. Sierra R, Benitez E, Leon C, Rello J. Prevention and diagnosis of ventilator-associated pneumonia: a survey on current practices in Southern Spanish ICUs. Chest 2005;128(3):1667-1673.

22. Wip C, Napolitano L. Bundles to prevent ventilator-associated pneumonia: how valuable are they? Curr Opin Infect Dis 2009;22(2):159166.
23. van Nieuwenhoven CA, Vandenbroucke-Grauls C, van Tiel FH, Joore HC, van Schijndel RJ, van der Tweel I, et al. Feasibility and effects of the semirecumbent position to prevent ventilator-associated pneumonia: a randomized study. Crit Care Med 2006;34(2):396-402.

24. Hess DR. Patient positioning and ventilator-associated pneumonia. Respir Care 2005;50(7):892-898; discussion 898-899.

25. Silvestri L, Gregori D, van Saene HK, Belli R, Blazic M. Semirecumbent position to prevent ventilator-associated pneumonia is not evidence based (letter). J Crit Care 2010;25(1):152-153; author response 153-154.

26. Carvajal C, Pobo A, Díaz E, Lisboa T, Llauradó M, Rello J. [Oral hygiene with chlorhexidine on the prevention of ventilator-associated pneumonia in intubated patients: a systematic review of randomized clinical trials]. Med Clin (Barc) 2010;135(11):491-497. Article in Spanish.

27. Parra Moreno ML, Arias Rivera S, de la Cal López MA, Frutos Vivar F, Cerdá Cerdá E, García Hierro P, Negro Vega E. [Effect of selective digestive decontamination on the nosocomial infection and multiresistant microorganisms incidence in critically ill patients]. Med Clin (Barc) 2002;118(10):361-364. Article in Spanish.

28. Dallas J, Kollef M. Oral decontamination to prevent ventilator-associated pneumonia: is it a sound strategy? Chest 2009;135(5):11161118 .

29. Silvestri L, van Saene HK, de la Cal MA, Sarginson RE, Thomann C. Prevention of ventilator-associated pneumonia by selective decontamination of the digestive tract. Eur Respir J 2008;32(1):241243.

30. Kollef MH. Selective digestive decontamination should not be routinely employed. Chest 2003;123(5 Suppl):464S-468S

31. Pileggi C, Bianco A, Flotta D, Nobile CG, Pavia M. Prevention of ventilator-associated pneumonia, mortality and all intensive care unit acquired infections by topically applied antimicrobial or antiseptic agents: a meta-analysis of randomized controlled trials in intensive care units. Crit Care 2011;15(3):R155.

32. Labeau SO, Vandijck DM, Brusselaers N, De Wandel D, Vogelaers DP, Blot SI. Reduction of ventilator-associated pneumonia: enhancing knowledge is important (letter). Intensive Care Med 2009;35(10): 1818-1819; author response 1820 .

33. Blot SI, Labeau S, Vandijck D, Van Aken P, Claes B. Evidencebased guidelines for the prevention of ventilator-associated pneumonia: results of a knowledge test among intensive care nurses. Intensive Care Med 2007;33(8):1463-1467.

34. Biancofiore G, Barsotti E, Catalani V, Landi A, Bindi L, Urbani L, et al. Nurses' knowledge and application of evidence-based guidelines for preventing ventilator-associated pneumonia. Minerva Anestesiol 2007;73(3):129-134.

35. El-Khatib MF, Zeineldine S, Ayoub C, Husari A, Bou-Khalil PK. Critical care clinicians' knowledge of evidence-based guidelines for preventing ventilator-associated pneumonia. Am J Crit Care 2010; 19(3):272-276.

36. Biancofiore G, Barsotti E, Catalani V, Landi A, Bindi L, Urbani L, et al. Nurses' knowledge and application of evidence-based guidelines for preventing ventilator-associated pneumonia. Minerva Anestesiol 2007;73(3):129-134.

37. Torres A, Ferrer M, Badia JR. Treatment guidelines and outcomes of hospital-acquired and ventilator-associated pneumonia. Clin Infect Dis 2010;51(Suppl 1):S48-S53. Erratum in: Clin Infect Dis 2010; 51(9): 1114 .

38. Silvestri L, van Saene HK, Gullo A, de la Cal MA. Guidelines for prevention, diagnosis, and treatment of ventilator-associated pneumonia (VAP) in the trauma patient (letter). J Trauma 2007;62(4): 1062-1064; author response 1064-1065.

39. Masterton RG, Galloway A, French G, Street M, Armstrong J, Brown $\mathrm{E}$, et al. Guidelines for the management of hospital-acquired pneu- 


\section{Prevention of Ventilator-Associated Pneumonia}

monia in the UK: report of the working party on hospital-acquired pneumonia of the British Society for Antimicrobial Chemotherapy. J Antimicrob Chemother 2008;62(1):5-34.

40. Labeau S, Vandijck D, Rello J, Adam S, Rosa A, Wenisch C, et al. Evidence-based guidelines for the prevention of ventilator-associated pneumonia: results of a knowledge test among European intensive care nurses. J Hosp Infect 2008;70(2):180-185.

41. Cason CL, Tyner T, Saunders S, Broome L. Nurses' implementation of guidelines for ventilator-associated pneumonia from the Centers for Disease Control and Prevention. Am J Crit Care 2007;16(1):28-36.

42. Heyland DK, Cook DJ, Dodek PM. Prevention of ventilator-associated pneumonia: current practice in Canadian intensive care units. J Crit Care 2002;17(3):161-167.

43. Ricart M, Lorente C, Diaz E, Kollef MH, Rello J. Nursing adherence with evidence-based guidelines for preventing ventilator-associated pneumonia. Crit Care Med 2003;31(11):2693-2696.

44. Meyer E, Sohr D, Gastmeier P, Geffers C. New identification of outliers and ventilator-associated pneumonia rates from 2005 to 2007 within the German Nosocomial Infection Surveillance System. J Hosp Infect 2009;73(3):246-252.
45. Vandijck DM, Labeau SO, Blot SI. Level of knowledge articulated by intensive care nurses and clinical decision-making. Intensive Crit Care Nurs 2008;24(1):6-7.

46. O'Keefe-McCarthy S, Santiago C, Lau G. Ventilator-associated pneumonia bundled strategies: an evidence-based practice. Worldviews Evid Based Nurs 2008;5(4):193-204.

47. Labeau S, Vandijck DM, Claes B, Van Aken P, Blot SI. Critical Care Nurses' Knowledge of Evidence-Based Guidelines for Preventing Ventilator-Associated Pneumonia: An Evaluation Questionnaire. Am J Crit Care 2007;16(4):371-377.

48. Scherzer R. Subglottic secretion aspiration in the prevention of ventilator-associated pneumonia: a review of the literature. Dimens Crit Care Nurs 2010;29(6):276-280.

49. Garcia R, Jendresky L, Colbert L, Bailey A, Zaman M, Majumder M. Reducing ventilator-associated pneumonia through advanced oraldental care: a 48-month study. Am J Crit Care 2009;18(6):523-532.

50. Sinuff T, Muscedere J, Cook D, Dodek P, Heyland D. Ventilatorassociated pneumonia: Improving outcomes through guideline implementation. J Crit Care 2008;23(1):118-125. 